\title{
Liderazgo docente: una mirada al camino de lo posible
}

\author{
M. Ed. Teresa Brais Quirós
}

Mucho se ha dicho y escrito sobre el tema del liderazgo. Este ensayo no pretende tomar el papel de un manual para convertir a los lectores en líderes, de esos estudios que abundan en las librerías; tampoco es material de capacitación organizacional para formación de líderes. Es más bien, una invitación para reflexionar, una propuesta para mirar el tema desde una perspectiva propia para adueñarse, no del concepto, sino de la acción. El mejor campo en el que el liderazgo puede adquirir significado y ser fructífero es aquel en el que el individuo se desenvuelve como profesional, y en el cual se considere que lo aportado puede ser valioso para los demás.

Para Bolívar (1997), el liderazgo es una forma especial de influencia relativa a inducir a otros a cambiar voluntariamente sus preferencias (acciones, supuestos y creencias), en función de tareas o proyectos. Quizás, la parte más importante de esta definición es que nos remite al concepto de cambio voluntario, no impuesto, sino generado, propiciado, a partir de esa influencia relativa. 
Cuando hablamos de liderazgo, el término en sí nos remite -casi inevitablemente- a figuras que, a lo largo de la historia, han encarnado el papel de líderes. Si nos remontamos a las perspectivas del ayer, nos encontramos con la figura de Jesús, quien desde la humildad y la sencillez guió los pasos de algunos en su época y dejó una huella que ha guiado a gran parte de la humanidad en la etapa de la historia denominada después de Cristo.

Por su lado, Alejandro Magno, en su conquista del Imperio Persa, lideró un ejército y lo llevó a superar obstáculos que no se limitaban a las tropas enemigas. Con esa conquista tenía un propósito, una visión y luchó, incansablemente, para alcanzar sus objetivos. Si la muerte no le hubiera interrumpido el paso, es muy posible que no sólo el Imperio Persa hubiera conquistado; pero eso no lo sabemos.

Hay líderes controversiales, que generan reacciones diversas y resulta difícil llegar a un acuerdo sobre la valoración de su obra. Un ejemplo de esto es el líder comunista Mao Tse-Tung quien consolidó la conformación de la República Popular de China, aunque sus métodos y el impacto de sus actos hayan sido cuestionados, por la mayor parte de la población.

También están los líderes que se han ganado el repudio generalizado, entre ellos Adolfo Hitler, con su obsesión enfermiza por conseguir la supremacía de la raza aria, lideró luchas nacionalistas y antisemitas que lo llevaron a límites reprochables. Él quería eliminar cualquier raza que pudiera ensuciar a los arios, especialmente las de los judíos y los árabes, pues para él la raza aria (europea blanca) era la más vigorosa. Así lo expresan Merle y De Saussure (1973, p.12): "Hitler reprimía su rencor contra el padre y escogía al judío como 'padre simbólico para odiar' porque el nacimiento dudoso de su padre permitía suponer que era judío". Sin embargo, nunca habría logrado hacerse visible y causar todo 
el daño que causó si no se hubiera constituido en el líder que fue.

Así como existen diferentes teorías sobre liderazgo, éstas nos dicen que hay diversos tipos de líderes, y diversas son las motivaciones que respaldan su liderazgo. Sería interesante preguntarse si esos grandes líderes mencionados anteriormente sabían que lo eran. Posiblemente sí, porque el liderazgo, luego de surgir, en parte gracias a los rasgos de personalidad de quien se constituye en líder, persiste gracias al ejercicio consciente y constante de quien se sabe responsable por una tarea, un grupo, una organización.

Ahora bien, apartémonos un poco de aquellos grandes que quedaron grabados en los libros de historia y pensemos en los líderes que están más cercanos a nuestra cotidianidad. Mire a su alrededor: quien inicia una empresa, quien escribe un libro, quien forma una familia, en cierta forma, aspira a convertirse en líder. Una vez más, las motivaciones son diversas, el líder surge porque su negocio así lo requiere, porque considera que sus ideas aportan algo a la sociedad, porque el grupo familiar necesita quién lo guíe. Un líder tiene buenas habilidades de comunicación, conoce su entorno, se adapta a las situaciones que la realidad le presenta y opera desde el fuerte respaldo que le dan sus valores y sus creencias.

$Y$ es aquí donde quisiera hacer el primer alto en el camino y preguntar al lector ¿tiene usted a alguien cerca, en su diario trajín, en ese ambiente donde usted trabaja, estudia o tiene sus horas de esparcimiento, que coincida con esas características? Estoy casi segura de que la respuesta es sí, todos conocemos a alguien así.

El mundo está lleno de líderes, líderes democráticos, autocráticos, participativos, permisivos, positivos, negativos. ¿Cuáles son los líderes que necesitamos, aquí y ahora? En mi opinión, los líderes que necesitamos son aquellos a 
los que hace referencia Uribe (2005), los que promueven la velocidad y la profundidad del cambio y, al mismo tiempo, conservan aquellos aspectos más significativos de la cultu$\mathrm{ra}$, valores y normas que son dignos de preservar.

Si volvemos los ojos a nuestra realidad nacional, debemos reconocer que el recientemente condecorado Benemérito de la Patria, don Jorge Manuel Dengo, es un buen ejemplo de lo que significa ser un líder. Durante toda su vida ha sido un promotor constante del cambio, pero no de cualquier cambio, sino de aquellas transformaciones que convenían a la sociedad costarricense, pero que, al mismo tiempo, fueron respetuosas con la cultura, los valores y las normas que nos definen y enorgullecen a los costarricenses.

Basta mencionar que las bases del Instituto Costarricense de Electricidad, la Oficina de Defensa Civil (precursora de la Comisión Nacional de Emergencias), la participación en el esfuerzo que llevó a conformar la Escuela de Agricultura de la Región del Trópico Húmedo (EARTH) son sólo tres ejemplos de la visión de un hombre que ayudó a construir una Costa Rica mejor. ¿Cuál cambio fue el que impulsó? El necesario. Supo leer y escuchar lo que la realidad decía y actuó en consecuencia. Eso le ha valido para que, aunque él no se haya dedicado a la enseñanza, algunos lo consideren como uno de los más grandes educadores que ha tenido Costa Rica, porque ha educado a todo un pueblo a partir de su obra.

Otro ejemplo en el ámbito nacional es el Dr. Franklin Chang, quien miró más allá de nuestras fronteras y ha llegado muy lejos y muy alto (literalmente). Llegó a ser astronauta, algo inalcanzable para los ojos de algunos. Ha contribuido a la investigación y al desarrollo de campos como la física. Y lo más importante, nunca dejó de mirar hacia sus raíces, tanto así que instaló en Guanacaste la sede de Ad Astra Rocket, la compañía que desarrolla el combustible a 
partir de plasma que nos podría llevar a Marte. Sí, también ha impulsado cambios necesarios. Aquel niño que una vez soñó con ser astronauta se ha convertido en líder e inspiración para muchos.

Interesante influencia la que algunos pueden ejercer en el futuro de otros. ¿Recuerda usted el momento en que eligió su profesión? ¿Hubo alguien que ejerciera alguna influencia? En el caso de los docentes, casi siempre la respuesta nos remite a la niña, al maestro, al profesor o a la profesora de secundaria que nos inspiró, y nos hizo creer que existía en nosotros la fibra necesaria para llegar a ser como ellos. ¿Fueron ellos líderes? Quizás sí, o quizás fueron únicamente modelos por seguir. Claro que no podemos pretender que todos nuestros estudiantes quieran convertirse en docentes, esa no es la idea.

Pero... ¿alguna vez nos hemos cuestionado si nosotros, los docentes, podemos ser líderes? Sí,... nosotros, sin esperar a ser director o directora, ni tener a cargo la coordinación de un proyecto. Históricamente, nos hemos limitado a ver como líderes a aquellos a quienes la institución denomina como tales. Claro que resulta más cómodo quedarnos en nuestra zona de confort y dejarnos guiar por el director, por los lineamientos del Ministerio. Los líderes formales tienen su razón de existir, pero eso no implica que sean los únicos líderes necesarios.

Pareciera que nos hemos cegado a la posibilidad de que nosotros, desde las aulas, también tengamos el potencial de ser líderes. Por costumbre, por comodidad, por falta de entusiasmo, por la razón que sea hemos atado nuestras manos y hemos sucumbido a la tentación de limitarnos a cumplir con nuestras responsabilidades.

Esto es lo que quiero cuestionar: los docentes tenemos la oportunidad de volvernos líderes, porque, como ya lo mencioné, el liderazgo se fortalece con el ejercicio consciente 
(porque tenemos que saber qué estamos haciendo y hacia dónde nos dirigimos) y constante (porque el liderazgo no permanece por arte de magia). Y no es el hecho de volvernos líderes por vanidad, ni por creernos poseedores de una verdad absoluta que queremos que otros sigan, ni por ansias de poder. No. Líderes, porque es una responsabilidad hacer algo productivo con nuestra privilegiada posición en la sociedad. Es muy fácil pasar desapercibido, llegar al aula a enseñar, entrar y salir de las vidas de nuestros estudiantes sin pena ni gloria, o en el peor de los casos ni siquiera entrar. Pero tener la voluntad de querer convertirse en aquel que hace que los estudiantes quieran ser mejores personas y ayudarles a construir las herramientas para hacerlo de forma efectiva, eso es un reto.

Hace poco, nuestro Ministro de Educación llevó una propuesta ante la Asamblea General de la UNESCO, el título de la ponencia cuestiona ¿Para qué educamos? (Garnier, 23 de octubre, 2007). El señor Ministro plantea que la alfabetización del siglo XXI significa algo más que leer, escribir y operar la aritmética básica; significa poder entender el mundo en que vivimos y expresarnos en los símbolos de nuestro tiempo, y esos son los símbolos de la ciencia, de la tecnología, de la política, del arte y de la cultura en todos los niveles. No podemos aspirar a menos. Culmina diciendo que: "Educamos, en fin, para vivir sin miedo en el afecto y la memoria de los demás: sólo así trascendemos como individuos; sólo así sobrevivimos como especie" (s.p.).

Una expectativa muy alta, dirían algunos. Considero que es una expectativa necesaria, que nos desafía y pone a prueba nuestras capacidades. ¿Quiénes son los llamados a educar? No miremos al lado. No busquemos otros responsables. Esta labor nos corresponde a los educadores, a los docentes, ¿y qué mejor forma de hacerlo que ejerciendo el liderazgo desde nuestra posición? 
Es cierto, existe una cuota de responsabilidad que le corresponde al liderazgo formal para generar las posibilidades de que nos convirtamos en líderes. Fullan (en Bolívar, 1997, p.3) comenta que: «En la medida en que el liderazgo del profesorado amplía la capacidad del centro escolar más allá del director, su función debe contribuir a crear las condiciones y capacidad para que cada uno de los profesores llegue a ser líder». Por su parte, Uribe (2005) hace énfasis en la necesidad de brindar a los profesores recursos para que, además de transmisores culturales, sean unos transformadores a partir del diagnóstico-observación de la realidad.

Aquí hay dos elementos claves que es muy importante resaltar y que se retomarán más adelante: primero, la necesidad de convertirnos en transformadores, y, segundo, la observación de la realidad como punto de partida.

Este enfoque del maestro como líder no es nuevo, ya que, de acuerdo con Uribe (2005), desde la década del ochenta, Bernar Bass hablaba del liderazgo transformacional y lo definía como "el comportamiento de ciertos directivos que tienden a convertir a sus profesores en líderes en la actividad educativa". Se les motiva mediante el logro; se despierta la conciencia acerca de la importancia que tienen los resultados escolares, y les generan altas expectativas. Bolívar (1997) se refiere a este concepto y plantea que el liderazgo ejercido de modo transformacional puede contribuir a modificar la cultura escolar, aumentando la capacidad individual y colectiva para resolver problemas, como ayudar a identificar los fines perseguidos por la organización y las prácticas adecuadas para alcanzarlos.

El meta-análisis de Waters, Marzano y McNulty (2003), del grupo de investigadores de Mid-continent Research for Education and Learning (McREL) comprueba que existe una relación significativa entre el liderazgo ejercido por 
los líderes formales (directores) y el rendimiento estudiantil. Llegaron a esta conclusión después de analizar los resultados de 30 años de investigación y la revisión de 70 estudios, en los cuales participaron 2894 centros educativos, aproximadamente 1.1 millones de estudiantes y unos 14000 docentes. Un gran esfuerzo de investigación, sin lugar a dudas.

Sin embargo, en estos abordajes persiste la concentración en el liderazgo formal y en su potencial como generador de resultados escolares, entendidos como notas en pruebas de rendimiento académico.

Yo quisiera ir un poco más allá y pensar en la posibilidad de que los docentes seamos capaces de influir en el desarrollo integral de los estudiantes, no sólo en el mejoramiento de sus calificaciones. Veámoslo así: en la mayoría de los casos, estos niños y jóvenes pasan con nosotros más tiempo del que pasan con sus padres. Nuestra labor de formadores y transformadores es fundamental. No podemos quedarnos con los brazos cruzados y esperar a que las condiciones estén creadas; más bien, debemos contribuir a crear esas condiciones para el cambio.

El convertirse en agentes de cambio es lo que caracteriza a los líderes. Conducen a las personas, a los grupos, a las organizaciones, a la sociedad, hacia el cambio. Surge la pregunta: ¿cuál cambio? Yo insisto: el necesario. Aquel cambio que sea exigido desde las condiciones históricas, sociales, culturales y políticas de nuestro medio. Aquel cambio reclamado por nuestra época y nuestras necesidades; pero no desde la individualidad, desde el yo egoísta, sino más bien desde la comprensión plena del nosotros, en la medida que somos conscientes de que formamos parte de un entorno y que nuestras acciones tienen y tendrán un impacto en los demás.

No se trata de imponer nuestras creencias, ni de tratar de vivir nuestros ideales a través de aquellos que creen 
en nosotros. Ese es el gran error de quienes se aprovechan de su posición para alcanzar fines individualistas gracias a la influencia sobre las demás personas. No es cuestión de hacer las veces del flautista de Hamelín, quien se hace seguir, sin que sus seguidores sepan hacia dónde van.

Se trata de lograr esa influencia relativa en los otros y promover cambios positivos en ámbitos diversos, pero generando, al mismo tiempo, conciencia sobre la pertinencia y la necesidad de tales cambios. Nuestro potencial es mayor del que imaginamos. Es cuestión de observar a nuestro alrededor y preguntarnos: ¿Cómo puedo influir positivamente en los niños y en los jóvenes con los que me relaciono? ¿Qué elementos de su realidad les están obstaculizando su desarrollo pleno como estudiantes y como seres humanos? ¿Se es líder sólo si se influye académica, política, social y económicamente en los discentes, o se podría hacer esto, también, en otros campos como los valores o en los hábitos de salud, por ejemplo?

Simulemos, brevemente, lo que sería un ejercicio de este liderazgo para la transformación de los niños, en este último campo mencionado.

Primero, partamos de un hecho tomado de la realidad costarricense (para eso basta con abrir un periódico o ver un noticiero). Recientemente, la Universidad de Costa Rica y el Instituto Costarricense de Investigación en Enseñanza en Nutrición y Salud (INCIENSA) publicaron los alarmantes resultados de un estudio que evidencia que el $20 \%$ de los escolares entre los 8 y los 10 años está a un paso de desarrollar diabetes tipo dos, una enfermedad que, hasta hace poco, aparecía con más frecuencia en adultos. Esta investigación llama la atención sobre el posible impacto de la obesidad y el sobrepeso en los menores.

Este estudio tuvo como origen una investigación anterior, realizada en el 2003, la cual reveló la presencia de 
obesidad en uno de cada cuatro niños y de sobrepeso en uno de cada tres. Los autores de este estudio indican que las causas de esta situación se pueden encontrar en la alimentación de los niños, caracterizada por el alto consumo de carbohidratos ricos en azúcares y en la falta de actividad física en los niños, tanto en la casa como en la escuela.

Segundo, remitamos estos hechos a nuestra realidad más cercana. ¿Es algo que observamos diariamente en nuestros estudiantes? En mi caso, la respuesta es sí: existe un elevado consumo de comidas rápidas, de comida chatarra en general; se da un escaso consumo de frutas y verduras, un sedentarismo preocupante. Es algo que está muy a la vista.

Tercero, aquí viene la pregunta clave de este planteamiento: ¿qué puedo hacer como docente para generar un cambio, una transformación que beneficie integralmente a mis estudiantes? Y el cuarto punto surge inevitablemente ¿Tengo la voluntad de hacer algo?

Para responder a la tercera pregunta como docente, de inglés por ejemplo, se podría revisar la planificación de las lecciones y cuestionarse dónde se podría incluir información o actividades tendientes a cambiar los hábitos de alimentación y de actividad física de los estudiantes. Lo primero que se debe hacer es informarse, buscar bibliografía, investigaciones y quizás el criterio de algún experto en la materia. Sí, claro que va más allá de las responsabilidades formales, pero el beneficio que esta iniciativa podría implicar, bien vale el esfuerzo. Podrían utilizarse diferentes estrategias para influir en ellos: se podría usar títeres, si se trata de los más pequeños; juegos de conjunto, si son un poco más grandes; debates e investigaciones, si son adolescentes; en fin, posibilidades hay muchas, todo depende de la respuesta que se le dé a la pregunta del cuarto punto. Es cuando la mediación pedagógica adquiere un papel de gran relevancia. 
¿Que cómo se relaciona esto con el liderazgo? En primer lugar, estaríamos conduciendo (ejerciendo una influencia relativa) a nuestros estudiantes a una transformación en sus hábitos, éste sería un impacto directo. Podría existir también un impacto indirecto en nuestros compañeros docentes, podríamos compartir nuestras ideas y generar interés en el desarrollo de estrategias similares. Y, eventualmente, podríamos estar impulsando una iniciativa institucional para realizar algún cambio que impacte esta área (cambios en la oferta alimenticia en la soda escolar, implementación de programas de clubes para realizar diversos tipos de actividad física, por ejemplo)

Repasemos, cómo podríamos ejercer un liderazgo efectivo y positivo, concebido éste como aquel que busca el trascender en los individuos, buscando siempre el bienestar integral. Los pasos son los siguientes:

1) Estar constantemente actualizados e informados sobre la realidad global.

2) Relacionar esa realidad con nuestro entorno inmediato.

3) Buscar y formular estrategias.

4) Decidirnos a ponerlas en práctica.

Este ejemplo se centró en una problemática específica, pero igual podríamos pensar en muchas otras áreas: educación para la paz, resolución de conflictos, salud sexual, respeto a los adultos mayores, conservación del ambiente, tolerancia hacia los grupos minoritarios, prevención del abuso de drogas, sólo por mencionar algunas.

Coincido con Uribe (2005) cuando plantea que en materia de liderazgo no hay verdades o patrones definitivos de acción. Por el contrario, el concepto de un balance adecuado o equilibrio entre conocimiento y habilidades es el 
que debe prevalecer. La dirección eficaz significa algo más que simplemente saber qué es lo que hay que hacer, pues es también reconocer cuándo es más adecuado llevarlo a cabo y por qué es necesario hacerlo.

En algún momento mencioné la importancia de que un líder tenga el respaldo de valores y de creencias, ya que esto no sólo es clave para adquirir la capacidad de reconocer cuáles son los cambios necesarios y enfocar los esfuerzos hacia el logro de los objetivos. También es fundamental para generar, en los otros, la confianza necesaria para inspirarles ese cambio voluntario que conducirá a alcanzar la meta propuesta.

Lo anterior nos presenta un reto que debemos enfrentar día a día, el desenvolvernos dentro de una práctica moral y ética, como seres humanos congruentes entre lo que decimos y lo que hacemos; personas con credibilidad para infundir respeto y confianza (no sólo entre los alumnos, sino también entre compañeros de trabajo, padres de familia, superiores, subalternos). Si el reto es constante, la autoevaluación debe ser también constante: ¿Estamos siendo íntegros y coherentes? ¿Estamos preparando y abonando el terreno para guiar a otros? ¿Somos conscientes de que nuestras acciones tienen una repercusión directa o indirecta en quienes nos rodean? En el fondo, sabemos que los contenidos que presentamos a la clase pasan a ser secundarios, ante la imperiosa necesidad de ser personas íntegras y capaces de ejercer una influencia positiva en los demás.

Propongo, entonces, que revisemos la forma en que hemos desempeñado nuestra labor y que mantengamos la mente y el espíritu abiertos ante la posibilidad de convertirnos en líderes. Pero no líderes conservadores y retrógrados, sino líderes modernos, para que generemos y apoyemos los cambios necesarios en aras de cambiar y mejorar el medio en el que nos desenvolvemos. En fin, líderes conscientes de la necesidad de actualizarse, de conocer las realidades nacional y 
mundial, pero también la realidad del entorno inmediato de nuestros estudiantes. Esas son las realidades que hay que observar, escuchar y sentir, en las cuales están cifradas las señales que, como el alquimista de Coelho, hay que leer para poder transformar la realidad actual en una mejor.

Así es que, creo necesario recordar: que nuestro deber como seres humanos, no es sólo informar, sino que lo más importante es formar y reformar, inspirando un mundo más humano. Es cocrear con nuestros influidos una sociedad más justa, solidaria, llena de valores, que nos permita ejercer nuestras habilidades y destrezas para el bien común. Y,... ¿cómo lograrlo?

Para ello, es muy importante, casi imperativo, que primero seamos camino de luz, esperanza, sabiduría, guías, ejemplo y apoyo desde donde estemos, sin importar cuál es el rol que estemos desempeñando, pues la historia la escribimos nosotros. La escribimos marcando la pauta, dibujando la senda por seguir, con el favor y la participación de los demás, siempre con miras a la construcción de un mundo mejor. Ése es el difícil, pero agradable y estimulante reto de cada día. Vale la pena intentarlo.

\section{REFERENCIAS BIBLIOGRÁFICAS}

Bolívar, A. (1997). Liderazgo, mejora y centros educativos. Trabajo presentado en la VIII Reunión del Grupo ADEME (Asociación para el Desarrollo y Mejora de la Escuela), celebrada en julio de 1995 en Madrid. Publicado en A. Medina (coord.): El liderazgo en educación. Madrid, UNED, 1997. Recuperado el 19 de octubre de 2007, de:

http://wwwn.mec.es/cide/espanol/investigacion/rieme/documentos/files/bolivar4/Bolivar4.pdf

Garnier, L. (27 de octubre, 2007). ¿Para qué educamos? Discurso pronunciado por el Ministro de Educación de Costa Rica, 
ante la Asamblea General de la UNESCO el 23 de octubre, 2007. [Versión electrónica] MEP sub/versivo. Recuperado el 30 de octubre, 2007 de: http:// www.leonardogarnier.com/index.php?option = com_content\&task $=$ view\& id $=544 \&$ Itemid $=134$

Merle, R. y De Saussure, R. (1973). Psicoanálisis de Hitler.

Buenos Aires: Editorial La Pléyade.

Uribe, M. (Julio, 2005). El liderazgo docente en la construcción de la cultura escolar de calidad. Un desafío de orden superior. En Revista PRELAC, №1 AÑO 1. Recuperado el 19 de octubre de 2007, de:

http://www.unesco.cl/medios/biblioteca/documentos/ liderazgo_docente_construccion_cultura_escolar_calidad_ desafio_orden_superior_mario_uribe_revista_prelac_espanol_1.pdf Waters, J. T., Marzano, R. J., \& McNulty, B. A. (2003). Balanced leadership: What 30 years of research tells us about the effect of leadership on student achievement. Aurora, CO: Mid-continent Research for Education and Learning. Recuperado el 19 de octubre de 2007, de:

http://www.mcrel.org/PDF/LeadershipOrganizationDevelopment/5031RR_BalancedLeadership.pdf 